\title{
Bypass surgery for left main coronary artery disease Reduced perioperative myocardial infarction with preoperative intra-aortic balloon counterpulsation ${ }^{\star}$
}

\author{
STEVEN R TAHAN, ALEXANDER S GEHA, GRAEME L HAMMOND, \\ LAWRENCE S COHEN, RENE A LANGOU
}

From the Section of Cardiology, Department of Internal Medicine, and Cardiothoracic Division, Department of Surgery, Yale University School of Medicine, New Haven, Connecticut, USA

SUMMARY From July 1975 to December 1977, 91 consecutive patients with left main coronary artery disease defined by cardiac catheterisation as $\geq 50$ per cent luminal narrowing underwent coronary bypass surgery. Prospective examination of the preoperative and postoperative clinical course of these patients was performed to determine the incidence of perioperative myocardial infarction. Intra-aortic balloon counterpulsation was instituted preoperatively in 35 patients, and these patients were classed as group A. Fifty-six patients did not receive the intra-aortic balloon pump and were classed as group B. Of 26 demographic, clinical, haemodynamic, and operative descriptors, only two were found to be significantly different between the two groups: the severity and the pattern of angina. Group A had a higher percentage of patients with class IV angina (80\% vs $45 \%$ ) and a greater proportion with unstable angina (37\% vs 7\%). Despite these differences group A patients had only a 3 per cent incidence of perioperative myocardial infarction while group B had a 23 per cent perioperative infarction rate. It is suggested that perioperative intra-aortic balloon counterpulsation can reduce the risk of perioperative myocardial infarction in patients with left main coronary artery stenosis.

Obstructive lesions involving the left main coronary artery have been associated with a guarded prognosis in patients with ischaemic heart disease. ${ }^{1-3}$ Early surgical intervention has become increasingly common for this disease, and many centres have reported a substantial relief of symptoms after operation. ${ }^{4-6}$ Furthermore, in comparing medical and surgical treatment for patients with left main stenosis several studies indicate a prolonged survival in surgically treated groups. ${ }^{5-7}$

Left main disease is itself a significant risk factor for operative mortality and perioperative myocardial infarction in coronary bypass surgery. Operative mortality has been reported to be two- to fivefold higher and perioperative myocardial infarction over 50 per cent more common in patients with significant left main narrowing. ${ }^{368}$

Experience with prophylactic and therapeutic intra-aortic balloon counterpulsation has shown it to be of value for patients with serious left ventri-

* This study was supported in part by a Yale University fluid grant. Received for publication 16 October 1979 cular dysfunction, impending myocardial infarction, or both, who were undergoing cardiac surgery. ${ }^{9-11}$ Evaluation of the prophylactic use of the intraaortic balloon pump for patients undergoing bypass grafting for left main disease comprises the subject of this report. We collected data retrospectively ${ }^{12}$ on 91 consecutive patients undergoing bypass surgery for left main coronary obstruction from July 1975 to December 1977 to determine prospectively if preoperative intra-aortic balloon pumping had any effect on the incidence of perioperative myocardial infarction.

\section{Patients and methods}

Data were collected on 91 consecutive patients shown to have greater than 50 per cent obstruction of the left main coronary artery who underwent. aortocoronary bypass grafting at Yale-New Haven Hospital from July 1975 to December 1977.

Diagnostic cardiac catheterisation consisted of pressure measurements, cardiac output determination, right anterior oblique left ventriculogram for 
analysis of regional wall motion, ${ }^{13}$ mitral regurgitation, and ejection fraction (calculated according to the method of Greene et al.), ${ }^{11}$ and selective coronary cinearteriography, all performed by standard techniques. A greater than 50 per cent stenosis of the left main coronary artery and a greater than 70 per cent stenosis for other coronary arteries was considered significant.

Coronary bypass surgery was performed within two weeks after angiography in all patients. All grafts to the left circumflex and right coronary arteries were performed using reversed autogenous saphenous veins. The left anterior descending artery was grafted using the left internal mammary artery in 37 patients, aortosaphenous bypass grafts in 45 patients, and double grafts using aortosaphenous vein grafts and the left internal mammary artery in nine patients. Dissection of the left internal mammary artery from the chest wall and proximal anastomoses of saphenous vein grafts were accomlished without cardiopulmonary bypass. Distal anastomoses were performed on full cardiopulmonary bypass with the heart in ventricular fibrillation, and aortic cross-clamping was used only when a dry field could not be obtained by local occlusion of the coronary artery. Each distal anastomosis was probed near its completion to ensure that the anastomotic communication was wider than the grafted coronary artery. The left ventricle was vented in all patients by a catheter passed through the right superior pulmonary vein or the ventricular apex into the left ventricular cavity. All blood aspirated into the extracorporeal circuit from the vent or cardiac suction lines was filtered through a millipore filter $\star$ before being returned to the oxygenator. $\dagger$ Whole blood was transfused only if perfusate haematocrit fell below 25 per cent, and serum potassium levels were carefully monitored and appropriately adjusted.

\section{DEFINITION OF VARIABLE STUDIES}

Perioperative myocardial infarction was defined as myocardial necrosis occurring within one week postoperatively and identified by serial electrocardiograms, necropsy, or both. All patients had daily standard 12 lead electrocardiograms from the day before operation until the seventh postoperative day with the first postoperative tracing obtained upon arrival in the surgical intensive care unit. Routine precautions were taken to ensure that praecordial electrocardiographic leads were recorded from the same praecordial place before and after

\footnotetext{
* Swank Micro-emboli Filter, Pioneer Filter Co, Beaverton, Oregon. † Temptrol Disposable Blood Oxygenator Model Q100, Bentley Laboratories Inc., Santa Anna, California; or Kolobine Disposable Membrane Ogygenator, Sci-Med, Minneapolis, Minnesota.
}

operation. The criterion for acute myocardial infarction was the development on serial electrocardiograms of new significant pathological $Q$ waves, equivalent to class $\mathrm{I}-1$ and $\mathrm{I}-2$ of the Minnesota Code. ${ }^{15}$ These new $Q$ waves were considered diagnostic of myocardial infarction if they were recorded from completely different sites from preoperative myocardial infarctions. New intraventricular conduction defects, new bundlebranch blocks, increasing size of previous $Q$ waves, and ST segment or $T$ wave changes without new pathological $Q$ waves were not considered diagnostic of myocardial infarctions. Rises in serum creatine kinase (CK), serum aspartate transaminase (AST), and CK-MB isoenzyme were not considered diagnostic of myocardial infarction. Mortality of perioperative myocardial infarction was considered to be death up to four weeks after coronary surgery.

\section{STATISTICAL METHODS}

Contingency table $x^{2}$ and multiple logistic regression model were used to analyse the data. ${ }^{16} \mathrm{~A}$ probability value less than $\mathbf{0 . 0 5}$ was considered statistically significant. When information on a specific clinical characteristic of a patient was not available, that patient was excluded from analysis of the particular variable.

\section{PATIENT GROUPINGS}

Thirty-five patients were treated preoperatively with intra-aortic balloon counterpulsation, $\ddagger$ and these patients were classed in this study as group A. Fifty-six patients did not receive the intra-aortic balloon pump and were classed as group B. The individual clinical decision regarding the insertion of a pump depended largely upon its availability, but maximal effort was made to assist patients with unstable angina with counterpulsation. When used, the intra-aortic balloon pump was introduced under local anaesthesia in the surgical intensive care unit through the common femoral artery via an end-to-side $10 \mathrm{~mm}$ 'dacron' graft and advanced into the descending thoracic aorta. When difficulties were encountered or anticipated, a wire-guided central lumen balloon catheter ${ }^{17}$ was introduced under direct fluoroscopy and pressure monitoring in the cardiac catheterisation laboratory. Details of introduction and management of the intra-aortic balloon pump have been previously described. ${ }^{18}$

In group $A$ patients the balloon pump was inserted before cardiac catheterisation and operation in 18, and before operation in 17. It was removed either at bypass surgery or up to 48 hours postoperatively in the surgical intensive care unit

$¥$ Avco Intra-aortic Balloon, Hoffman-LaRoche Inc., Cranbury, New Jersey. 
in all cases. In no instance was the intra-aortic balloon pump left on longer than seven days (average four days).

\section{DEMOGRAPHIC CHARACTERISTICS}

Table 1 displays variables relating to the past medical history and physical examination of this group of 91 patients with left main stenosis. It can be seen that the following variables were distributed approximately equally between the 35 group A and 56 group B patients: age over 55, sex, history of previous myocardial infarction, history of congestive heart failure, positive family history (ischaemic heart disease in immediate family member before age 55), evidence of peripheral vascular disease, history of smoking, and propranolol dosage and tapering. Sixty-three per cent of the population was over age $55 ; 80$ per cent were male; 43 per cent had a history of previous myocardial infarction; 28 per cent had symptoms of congestive heart failure; 62 per cent had a positive family history; 26 per cent showed signs of peripheral vascular disease; 64 per cent had a positive smoking history; 60 per cent had been on more than $160 \mathrm{mg}$ propranolol per day, and 8 per cent had propranolol therapy abruptly stopped without tapering before operation.

Statistically significant differences between the two groups were found in three of the studied demographic descriptors: severity of angina pectoris, pattern of angina pectoris, and use of propranolol before surgery for control or attempted control of symptoms. Eighty per cent of group A patients had New York Heart Association (NYHA) class IV angina while only 45 per cent of group B patients had class IV symptoms $(p<0 \cdot 05)$. Unstable angina (defined as constant chest pain at rest of at least 20 minutes' duration, refractory to medical therapy with beta-blockers and nitrates) was present in 37 per cent of group A patients compared with 7 per cent of group B patients $(p<0 \cdot 05)$. Propranolol was used before admission for operation in 97 per cent of group A patients compared with 76 per cent of those in group $B(p<0.02)$. Of note is that there was no significant difference in method of cessation of propranolol therapy among patients receiving the beta-blocker in the two groups. These three demographic indices outline, then, a group A population with clinically more severe angina pectoris than group B.

Similarly, radiological, haemodynamic, and angiographic data are shown in Table 2. A comparable distribution between the two groups can be seen for cardiac enlargement (CT ratio $>50 \%$ ), abnormal ejection fraction, raised left ventricular enddiagstolic pressure (LVEDP), evidence of mitral regurgitation, and presence of triple vessel disease and of abnormal segmental wall motion. Eighteen per

Table 1 Demographic characteristics: medical history and physical examination

\begin{tabular}{|c|c|c|c|c|}
\hline & Total & Group $A(I A B P)$ & Group $B($ no $I A B P)$ & $p$ value \\
\hline $\begin{array}{l}\text { Number of patients } \\
\text { Age (y) }\end{array}$ & 91 & 35 & 56 & \\
\hline $\begin{array}{l}<55 \\
\geqslant 55\end{array}$ & $\begin{array}{l}34 / 91(37 \%) \\
57 / 91(63 \%)\end{array}$ & $\begin{array}{l}10 / 35(29 \%) \\
25 / 35(71 \%)\end{array}$ & $\begin{array}{l}24 / 56(43 \%) \\
32 / 56(57 \%)\end{array}$ & $\begin{array}{l}\text { NS } \\
\text { NS }\end{array}$ \\
\hline \multicolumn{5}{|l|}{ Sex } \\
\hline M & $73 / 91(80 \%)$ & $31 / 35(89 \%)$ & $42 / 56(75 \%)$ & NS \\
\hline $\mathrm{F}$ & $18 / 91(20 \%)$ & $4 / 35(11 \%)$ & $14 / 56(25 \%)$ & NS \\
\hline Previous myocardial infarction & $37 / 87(43 \%)$ & $16 / 35(46 \%)$ & $21 / 52(40 \%)$ & NS \\
\hline History of congestive heart failure & $24 / 87(28 \%)$ & $10 / 35(29 \%)$ & $14 / 52(27 \%)$ & NS \\
\hline + Family history & $54 / 87(62 \%)$ & $22 / 33(67 \%)$ & $32 / 54(59 \%)$ & NS \\
\hline History of hypertension & $29 / 90(32 \%)$ & $10 / 35(29 \%)$ & $19 / 55(35 \%)$ & NS \\
\hline Peripheral vascular disease & $24 / 91(26 \%)$ & $7 / 35(20 \%)$ & $17 / 56(30 \%)$ & NS \\
\hline Smoking & $58 / 90(64 \%)$ & $21 / 34(62 \%)$ & $37 / 56(66 \%)$ & NS \\
\hline \multicolumn{5}{|l|}{ Angina } \\
\hline \multirow[t]{4}{*}{ Severity: } & $2 / 91(1 \%)$ & $0 / 35(0 \%)$ & $2 / 56(3 \%)$ & NS \\
\hline & $14 / 91(15 \%)$ & $3 / 35(9 \%)$ & $11 / 56(20 \%)$ & NS \\
\hline & $22 / 91 \quad(24 \%)$ & $4 / 35(11 \%)$ & $18 / 56(32 \%)$ & NS \\
\hline & $53 / 91(58 \%)$ & $28 / 35(80 \%)$ & $25 / 56(45 \%)$ & $<0.05$ \\
\hline \multirow[t]{3}{*}{ Pattern: } & $22 / 91(24 \%)$ & $6 / 35(17 \%)$ & $16 / 56(29 \%)$ & NS \\
\hline & $52 / 91(57 \%)$ & $16 / 35(46 \%)$ & $36 / 56(64 \%)$ & NS \\
\hline & $17 / 91(19 \%)$ & $13 / 35(37 \%)$ & $4 / 56(7 \%)$ & $<0.05$ \\
\hline \multicolumn{5}{|l|}{ Propranolol } \\
\hline \multirow{3}{*}{$\begin{array}{l}\text { None } \\
<160 \mathrm{mg} \text { daily } \\
\geqslant 160 \mathrm{mg} \text { daily }\end{array}$} & $14 / 89(16 \%)$ & $1 / 35(3 \%)$ & $13 / 54(24 \%)$ & $<0.02$ \\
\hline & $22 / 89(25 \%)$ & $6 / 35(17 \%)$ & $16 / 54(30 \%)$ & NS \\
\hline & $53 / 89(60 \%)$ & $28 / 35(80 \%)$ & $25 / 54(46 \%)$ & NS \\
\hline \multicolumn{5}{|l|}{ Propranolol tapering } \\
\hline \multirow{4}{*}{$\begin{array}{l}\text { No propranolol } \\
\text { Abrupt withdrawal } \\
\text { Tapered or discontinued } 48 \text { hours } \\
\text { before operation }\end{array}$} & $14 / 75(19 \%)$ & $1 / 35(3 \%)$ & $13 / 40(32 \%)$ & $<0.01$ \\
\hline & $6 / 75(8 \%)$ & $1 / 35(3 \%)$ & $5 / 40(12 \%)$ & NS \\
\hline & & & & \\
\hline & $53 / 75(71 \%)$ & $33 / 35(94 \%)$ & $22 / 40(55 \%)$ & NS \\
\hline
\end{tabular}

IABP, intra-aortic balloon pump. 
Table 2 Demographic characteristics: chest $\mathrm{x}$-ray and cardiac catheterisation

\begin{tabular}{|c|c|c|c|c|}
\hline & Total & Group $A(I A B P)$ & Group $B($ no $I A B P)$ & $p$ value \\
\hline $\begin{array}{l}\text { Cardiac enlargement } \\
\text { Vessels diseased }\end{array}$ & $16 / 91(18 \%)$ & $6 / 35(17 \%)$ & $10 / 56(18 \%)$ & NS \\
\hline $\begin{array}{l}\text { LMCA only } \\
\text { LMCA + RCA }\end{array}$ & $\begin{array}{l}14 / 91(15 \%) \\
77 / 91(85 \%)\end{array}$ & $\begin{array}{c}2 / 35(6 \%) \\
33 / 35(94 \%)\end{array}$ & $\begin{array}{l}12 / 56(21 \%) \\
44 / 56(79 \%)\end{array}$ & $\begin{array}{l}\text { NS } \\
\text { NS }\end{array}$ \\
\hline $\begin{array}{l}\text { Ejection fraction } \\
\quad \geqslant 0.60 \\
<0.60\end{array}$ & $\begin{array}{l}39 / 75(52 \%) \\
36 / 75(48 \%)\end{array}$ & $\begin{array}{l}14 / 29(48 \%) \\
15 / 29(52 \%)\end{array}$ & $\begin{array}{l}25 / 46(54 \%) \\
21 / 46(46 \%)\end{array}$ & $\begin{array}{l}\text { NS } \\
\text { NS }\end{array}$ \\
\hline $\begin{array}{l}\text { LVEDP } \\
\quad \leqslant 12 \mathrm{mmHg} \\
>12 \mathrm{mmHg} \\
\text { Mitral regurgitation } \\
\text { Abnormal segmental wall motion }\end{array}$ & $\begin{array}{c}31 / 84(37 \%) \\
53 / 84(63 \%) \\
6 / 81(7 \%) \\
53 / 84(63 \%)\end{array}$ & $\begin{array}{l}11 / 34(32 \%) \\
23 / 34(68 \%) \\
2 / 35(6 \%) \\
25 / 34(73 \%)\end{array}$ & $\begin{array}{c}20 / 50(40 \%) \\
30 / 50(60 \%) \\
4 / 46(9 \%) \\
28 / 50(56 \%)\end{array}$ & $\begin{array}{l}\text { NS } \\
\text { NS } \\
\text { NS } \\
\text { NS }\end{array}$ \\
\hline
\end{tabular}

LMCA, left main coronary artery; LVEDP, left ventricular end-diastolic pressure; RCA, right coronary artery.

cent of the total population had cardiac enlargement; 48 per cent had an ejection fraction of less than 0.60 ; 63 per cent had LVEDP of greater than $12 \mathrm{mmHg}$; 7 per cent had evidence of mitral regurgitation; 85 per cent had disease of the right coronary artery (RCA) in addition to the left system; and 63 per cent had abnormal segmental wall motion on left ventriculogram.

Table 3 displays operative data for the group. An approximately equal distribution of patients receiving the intra-aortic balloon pump and those not was seen for number of major diseased vessels not grafted (incomplete revascularisation), cardiopulmonary bypass time, anoxia time (aortic crossclamping), and number of grafted vessels. Sixtyseven per cent of the population had complete revascularisation; 58 per cent had a cardiopulmonary bypass time longer than 90 minutes; 41 per cent had anoxia times of greater than 30 minutes; and 69 per cent received three or more grafts. No differences in operative indices were seen between the two groups.

\section{Results}

Perioperative myocardial infarction occurred in 15 per cent of the total population of 91 patients with left main disease. An analysis of incidence of perioperative myocardial infarction for previously reported or suggested risk factors is displayed in Table 4. We found no significant association between perioperative myocardial infarction and age over 55, sex, severity or pattern of anginal pain, the presurgical use of beta-blockers, dosage of propranolol if used, method of propranolol discontinuation, cardiac enlargement, mitral regurgitation, abnormal segmental wall motion, abnormal ejection fraction, raised LVEDP, anoxia time, disease of the right coronary artery, or incomplete revascularisation. A significant association was seen, however, between cardiopulmonary bypass time greater than 90 minutes $(p<0.05)$ and suggested for more than three grafts performed $(p<0 \cdot 10)$. Twenty-three per cent of patients with cardiopulmonary bypass times of longer than 90 minutes infarcted compared

Table 3 Operative history

\begin{tabular}{|c|c|c|c|c|}
\hline & Total & Group $A(I A B P)$ & Group $B$ (no $I A B P)$ & $p$ value \\
\hline \multicolumn{5}{|c|}{ Number of grafts performed } \\
\hline 1 & $1 / 91(1 \%)$ & $0 / 35(0 \%)$ & $1 / 56(2 \%)$ & NS \\
\hline 3. & $56 / 91(62 \%)$ & $26 / 35(74 \%)$ & $30 / 56(54 \%)$ & NS \\
\hline$\geqslant 4$ & $7 / 91(8 \%)$ & $4 / 35(11 \%)$ & $3 / 56(5 \%)$ & NS \\
\hline \multicolumn{5}{|c|}{ Diseased vessels not grafted } \\
\hline None & $61 / 91(67 \%)$ & $24 / 35(69 \%)$ & $37 / 56(66 \%)$ & NS \\
\hline LCF & $21 / 91(23 \%)$ & $6 / 35(17 \%)$ & $15 / 56(27 \%)$ & NS \\
\hline RCA & $7 / 91(8 \%)$ & $4 / 35(11 \%)$ & $3 / 56(5 \%)$ & NS \\
\hline \multicolumn{5}{|c|}{ Cardiopulmonary bypass time } \\
\hline$\leqslant 90$ seconds & $38 / 91(42 \%)$ & $13 / 35(37 \%)$ & $25 / 56(45 \%)$ & NS \\
\hline$>90$ seconds & $53 / 91(58 \%)$ & $22 / 35(63 \%)$ & $31 / 56(55 \%)$ & NS \\
\hline \multicolumn{5}{|l|}{ Anoxia time } \\
\hline 0 & $27 / 91(30 \%)$ & $11 / 35(31 \%)$ & $16 / 56(29 \%)$ & NS \\
\hline $0-30$ seconds & $27 / 91(30 \%)$ & $8 / 35(23 \%)$ & $19 / 56(34 \%)$ & NS \\
\hline $31-60$ seconds & $30 / 91(33 \%)$ & $11 / 35(31 \%)$ & $19 / 56(34 \%)$ & NS \\
\hline
\end{tabular}

I ABP, intra-aortic balloon pump; LAD, left anterior descending coronary artery; LCF, circumflex coronary artery; RCA, right coronary artery. 
Table 4 Patients sustaining perioperative myocardial infarctions



LAD, left anterior descending; LCF, circumflex coronary artery; LMCA, left main coronary artery; LVEDP, left ventricular end-diastolic pressure; RCA, right coronary artery.

with only 5 per cent of those with cardiopulmonary bypass times of less than 90 minutes. Twenty-nine per cent of patients receiving four or more grafts infarcted compared with 12 per cent with less than four grafts.

In the intra-aortic balloon pump group (group A) only one patient infarcted $(1 / 35,3 \%)$ perioperatively compared with 13 in the group not receiving the balloon pump $(13 / 56,23 \%), p<0.05$. We ran a similar analysis of reported risk factors for perioperative myocardial infarction against the results in each group. As with the total population, both groups showed an association of perioperative myocardial infarction with cardiopulmonary bypass 
times of greater than 90 minutes $(p<0.05)$. In group $B$, more than three grafts performed was a suggested risk for perioperative myocardial infarction $(67 \%$ vs $23 \%, \mathrm{p}<0.05)$ as was the presence of triple vessel disease $(27 \%$ vs $8 \%, \mathrm{p}<0.05)$.

Statistical analysis of the interdependence of risk factors was performed to determine if any combination was additive. Table 5 displays data showing an additive effect for the combination of triple vessel disease and not using the intra-aortic balloon pump and for the combination of cardiopulmonary bypass times longer than 90 minutes and not using the intra-aortic balloon pump. The incidence of perioperative myocardial infarction in triple vessel disease and not using the intra-aortic balloon pump was 27 per cent while the absence of triple vessel disease and using the balloon yielded a nil infarction rate $(p<0.05)$. Similarly, perioperative myocardial infarction was seen in 35 per cent of patients with prolonged cardiopulmonary bypass times not using the intra-aortic balloon pump compared with none with shorter cardiopulmonary bypass times using the balloon $(p<0.05)$. Other combinations of risk factors did not show a significant additive relation to perioperative myocardial infarction.

The overall mortality in this operated series in patients with left main coronary stenoses was 8.7 per cent $(8 / 91)$. The mortality of perioperative myocardial infarction in this study was 36 per cent (5/14) while patients not sustaining a myocardial infarction had an operative mortality of 3.9 per cent (3/77). Of the three patients who died in the noninfarcted population, one was in group $A$ and two were in group B. All three patients died as a result of left ventricular failure but there was no evidence of perioperative myocardial infarction either by electrocardiographic criteria or by necropsy.

In addition to the 35 successful preoperative insertions of the intra-aortic balloon pump there were four unsuccessful attempts and nine successful intra- or postoperative placements. In three of the unsuccessful attempts the intra-aortic balloon pump could not be advanced beyond the bifurcation

Table 5 Perioperative myocardial infarction

\begin{tabular}{clcc}
\hline & $\begin{array}{l}\text { Patients with } \\
\text { IABP }\end{array}$ & $\begin{array}{l}\text { Patients without } \\
\text { IABP }\end{array}$ & p value \\
\hline Vessels diseased & & & \\
LMCA only & $0 / 2(0 \%)$ & $1 / 12(8 \%)$ & NS \\
LMCA + RCA & $1 / 33(3 \%)$ & $12 / 44(27 \%)$ & $<0.05$ \\
CPB time & & $2 / 25(8 \%)$ & NS \\
$\quad \leqslant 90$ seconds & $0 / 13(0 \%)$ & $11 / 31(35 \%)$ & $<0.05$ \\
$>90$ seconds & $1 / 22(5 \%)$ & $5 \%$ & \\
\hline
\end{tabular}

CPB, cardiopulmonary bypass time; IABP, intra-aortic balloon pump; LMCA, left main coronary artery; RCA, right coronary artery. of the abdominal aorta and was withdrawn without complication. The fourth led to an aortic dissection that healed without surgical intervention. There were two postoperative groin infections, and no cases of arterial insufficiency. The overall complication rate was 6 per cent, 3/48 (Table 6).

\section{Discussion}

In this study we report on 91 consecutive patients with left main coronary artery disease undergoing bypass surgery. Thirty-five patients received the intra-aortic balloon pump preoperatively and 56 did not. Statistically significant differences between the two groups among 26 demographic, clinical, haemodynamic, and operative descriptors were found only in the severity of angina pectoris, pattern of angina pectoris, and presurgical use of betablockers. These three indices outlined the group receiving the intra-aortic balloon pump as consisting of a higher percentage of patients with more severe anginal symptoms.

Perioperative myocardial infarction occurred in 15 per cent of the overall sample using very stringent $Q$ wave electrocardiographic criteria. This is comparable to previously reported series in which the incidence of perioperative myocardial infarction ranged from $10 \cdot 7$ to 37.5 per cent. ${ }^{6} 1920$ It is likely that this report underestimates the true incidence of perioperative myocardial infarction, since the rigid electrocardiographic criteria employed exclude a significant number of patients with possible, but less striking evidence of myocardial necrosis. In particular, patients sustaining nontransmural myocardial damage would probably be excluded by our criteria, as well as those sustaining transmural lesions in such sites that electrocardiographic changes were obscured by previous infarctions. Furthermore, while transient or permanent intraventricular conduction abnormalities might suggest myocardial damage, we did not consider these changes conclusive evidence for infarction. The use of serial serum enzyme determinations was

Table 6 Complications of intra-aortic balloon placement or attempted placement

\begin{tabular}{lc}
\hline Intra-aortic balloon pump insertion & \\
Before operation & $35-$ Group A \\
During or after operation & 9 Group B \\
Unsuccessful attempts & 4 \\
& - \\
Total & 48 \\
Complications & $2 / 48(4 \%)$ \\
Infection (groin or sepsis) & $1 / 48(2 \%)$ \\
Aortic dissection & $0 / 48(0 \%)$ \\
Arterial insufficiency & $3 / 48(6 \%)$ \\
Overall & \\
\hline
\end{tabular}


felt to be an unreliable method for determining perioperative infarction, as serum $\mathrm{CK}$ and AST levels are raised during surgery by musculoskeletal trauma, ${ }^{21}$ and $\mathrm{CK}-\mathrm{MB}$ isoenzyme measurements have been shown to overestimate the incidence of perioperative myocardial infarction after bypass surgery. ${ }^{22}$

No correlation was found between infarction and preoperative clinical presentation, haemodynamic factors such as raised LVEDP or abnormal ejection fraction, abnormalities of contraction, or correlation to additional disease of the right coronary artery. There was also no association with incomplete revascularisation or time of aortic cross-clamping. A significant association of perioperative myocardial infarction was found in patients with prolonged cardiopulmonary bypass times and suggested for more than three grafts performed. However, it is difficult to draw conclusions regarding the importance of multiple grafts, because of the few patients in our series having more than three grafts. Several investigators have found bypass time and number of grafts performed to be related to the frequency of perioperative myocardial infarction..$^{81923} \mathrm{We}$ recognise, however, that cardiopulmonary bypass times of longer than 90 minutes are frequently associated with technically difficult anastomoses between the graft and extensively diseased vessels. Our series differed from the results of Brewer et al..$^{19}$ but concurred with others ${ }^{8}{ }^{23}$ in that severity and pattern of anginal pain were not related to the frequency of perioperative myocardial infarction in the overall group. We also found no correlation of perioperative myocardial infarction to the number of diseased vessels or to incomplete revascularisation, in contrast to previous reports. ${ }^{19} 20$ We feel that some of these differences may well be related to the beneficial effects of the intra-aortic balloon pump as analysis of patients without the pump suggests more parallels to previously reported results.

While group A (intra-aortic balloon pump) had a greater proportion of patients with more severe clinical presentation, we found this group to have a significantly lower incidence of perioperative myocardial infarction than group B (3\% vs $23 \%$, $\mathrm{p}<0.05$ ). Feola and colleagues reported a similar reduction in incidence of perioperative myocardial infarction using the intra-aortic balloon pump before bypass surgery in patients with poor left ventricular function. ${ }^{10}$ They found a 30.4 per cent perioperative myocardial infarction rate in the group not assisted with preoperative counterpulsation and only 4 per cent in the assisted group.

Statistical analysis of combinations of risk factors for patients with left main disease showed a significantly additive risk for perioperative myocardial infarction when the intra-aortic balloon pump was not used in the presence of disease of the right coronary artery. A similar additive risk was seen when the pump was not used and the cardiopulmonary bypass time prolonged.

The mortality of myocardial infarction was 36 per cent in this series, while patients not sustaining perioperative infarction had a mortality of 3.9 per cent. This high rate shows the malignant nature of infarction for patients with left main disease and is in accord with recent reports. ${ }^{23-25}$

Of 48 attempts at introduction of an intra-aortic balloon pump there were three complications: one aortic dissection that healed without operation and two groin infections. No patient in the intraaortic balloon pump group suffered peripheral vascular disease as a result of this procedure. This is comparable with the experience of several investigators who have reported a 0 to 17 per cent overall complication rate and a 0 to 15 per cent rate of arterial insufficiency after balloon placement. ${ }^{26-29}$

Our results suggest that the risk of perioperative infarction can be reduced by the preoperative institution of intra-aortic balloon counterpulsation in patients with left main disease undergoing bypass surgery. Even in the clinical setting of mild symptoms and normal or near normal haemodynamics, the perioperative infarction rate is high, and careful preoperative intra-aortic balloon pump introduction can be of significant benefit.

\section{References}

${ }^{1}$ Cohen MV, Gorlin R. Main left coronary artery disease. Clinical experience from 1964-1974. Circulation 1975; 52: $275-85$.

${ }^{2}$ DeMott H, Bonchek LI, Rösch J, Anderson RP, Starr A, Rahimtoola SH. Left main coronary artery disease. Risks of angiography, importance of coexisting disease of other coronary arteries and effects of revascularization. Am $\mathcal{F}$ Cardiol 1975; 36: 136-41.

${ }^{3}$ Read RC, Murphy ML, Hutlgren HN, Takaro T. Survival of men treated for chronic stable angina pectoris. $\mathcal{F}$ Thorac Cardiovasc Surg 1978; 75: 1-16.

${ }^{4}$ McConahay DR, Killen DA, McCallister BP, et al. Coronary artery bypass surgery for left main coronary artery disease. Am 7 Cardiol 1976; 37: 885-9.

${ }^{5}$ Oberman A, Harrell RR, Russell RV Jr, Kouchoukos NT, Holt JH Jr, Rackley CE. Surgical versus medical treatment in disease of the left main coronary artery. Lancet 1976; 2: 591-4.

${ }^{6}$ Takaro T, Hultgren HN, Lipton MJ, Detre KM. The VA cooperative randomized study for surgery for coronary arterial occlusive disease. II. Subgroup with significant left main lesions. Circulation 1976; 53 and 54: Suppl III:107-17.

${ }^{7}$ Manley J, Friedberg HD, Auer J, Johnson WD. Late follow-up (up to five years) after coronary surgery in 
comparison to reported medical series (abstract). Am f Cardiol 1975; 35 : 155.

${ }^{8}$ Langou RA, Wiles JC, Peduzzi PN, Hammond GL, Cohen LS. Incidence and mortality of perioperative myocardial infarction in patients undergoing coronary artery byjpass grafting. Circulation 1977; 55 and 56: Suppl II : 54-8.

${ }^{9}$ Gold HK, Leinbach RC, Sanders CA, Buckley MJ, Mundth ED, Austen WG. Intra-aortic balloon pumping for control of recurrent myocardial ischemia. Circulation 1973; 47: 1197-203.

${ }^{10}$ Feola M, Wiener L, Walinsky $\mathrm{P}$, et al. Improved survival after coronary bypass surgery in patients with poor left ventricular function: role of intra-aortic balloon counterpulsation. Am $\mathcal{f}$ Cardiol 1977; 39: 1021-26.

${ }^{11}$ Lefemine AA, Kosowsky B, Madoff I, Black H, Lewis M. Results and complications of intra-aortic balloon pumping in surgical and medical patients. Am $\mathfrak{f}$ Cardiol 1977; 40: 416-20.

${ }^{12}$ Feinstein AR. Clinical biostatistics. St. Louis: C. V. Mosby, 1977: 91, 197, 305-6.

${ }^{13}$ Herman MV, Gorlin R. Implications of left ventricular asynergy. Am $\mathcal{F}$ Cardiol 1969; 23 : 538-47.

${ }^{14}$ Greene DE, Carlisle R, Grant C, Bunnell IL. Estimation of left ventricular volume by one plane cineangiography. Circulation 1967; 35: 61-9.

${ }^{15}$ Blackburn H, Keys A, Simonson E, Rautaharju P, Punsar S. The electrocardiogram in population studies: a classification system. Circulation 1960; 21 : 1160-75.

${ }^{16}$ Colton T. Statistics in medicine. Boston: Little Brown, 1974: 284.

${ }^{17}$ Wolfson S, Geha AS, Hammond GL, Langou RA, Cohen LS. Preliminary report: modification of intraaortic balloon for pressure measurements, contrast injection and guide wire passage (abstract). Am $\mathcal{f}$ Cardiol 1977; 29: 260.

${ }^{18}$ Beckman CB, Geha AS, Hammond GL, Baue AE. Results and complications of intra-aortic balloon counterpulsation. Ann Thorac Surg 1977; 24: 550-9.

${ }^{19}$ Brewer DL, Bilbro RH, Bartel AG. Myocardial infarction as a complication of coronary bypass surgery. Circulation 1973; 47: 58-64.

${ }^{20}$ Espinoza J, Lipski J, Litwak R, Donoso E, Dack S. New $Q$ waves after coronary bypass surgery for angina pectoris. Am $\mathcal{F}$ Cardiol 1974; 33 : 221-4.
${ }^{21}$ Dixon SH, Limbird LE, Roe CR, Wagner GS, Oldham HN, Sabistow DO. Recognition of postoperative myocardial infarction (abstract). Circulation 1972; 45 and 46: Suppl II : 69.

${ }^{22}$ Righetti A, Crawford MH, O'Rourke RR, et al. Detection of perioperative myocardial damage after coronary bypass graft surgery. Circulation 1977; 55: 173-8.

${ }^{23}$ Wiles JC, Peduzzi PN, Hammond GL, Cohen LS, Langou RA. Preoperative predictors of operative mortality for coronary bypass grafting in patients with unstable angina pectoris. Am $\mathcal{F}$ Cardiol 1977; 39: 939-43.

${ }^{24}$ Rose MR, Glassman E, Isom OW, Spencer FC. Electrocardiographic and serum enzyme changes of myocardial infarction after coronary artery bypass surgery. Am $\mathcal{f}$ Cardiol 1974; 33: 215-20.

${ }^{25}$ Cannom DS, Miller DC, Shumway NE, et al. The long-term follow-up of patients undergoing saphenous vein bypass surgery. Circulation $1974 ; 49: 77-85$.

${ }^{26}$ Lawrence GH, Riggins RCK, Johnston RR, Balfour RI, Thompson GE. Intra-aortic balloon counterpulsation for the treatment and prevention of cardiogenic shock. Am $\mathcal{F}$ Surg 1974; 128: 188-94.

${ }^{27}$ Hochberg S. Report of the IABP monthly usage program. In: Transactions of the second meeting of users of the Avco intra-aortic balloon pump, 17 November 1974. Cranberry, NJ : Roche Medical Electronics, 1974 : 85.

${ }^{28} \mathrm{O}$ 'Rourke MF, Chang VP, Windsor HM, et al. Acute severe cardiac failure complicating myocardial infarction. Experience with 100 patients referred for consideration of mechanical left ventricular assistance. $\mathrm{Br}$ Heart $\mathcal{f} 1975$; 37: 169-81.

${ }^{29}$ Willerson JT, Curry GC, Watson JT, et al. Intraaortic balloon counterpulsation in patients in cardiogenic shock, medically refractory left ventricular failure and/or recurrent ventricular tachycardia. $\mathrm{Am} \mathcal{F} \mathrm{Med}$ 1975; 58: 183-91.

Requests for reprints to Dr Rene A Langou, Yale University School of Medicine, Cardiology Section, 87 LMP, 333 Cedar Street, New Haven, Connecticut 06510 , USA. 